\title{
Distribution of Dose-Rates and Deposition of Radioactive Cesium by the Airborne Monitoring Surveys
}

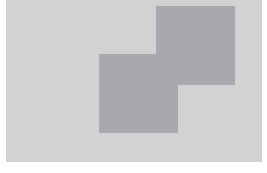

\author{
Japan Atomic Energy Agency, \\ Tatsuo Torii, Yukihisa Sanada and Takeshi Sugita \\ Japan Map Center, Kei Tanaka
}

To survey the impact of radioactive cesium emitted into the atmosphere and deposited into the ground surface as a result of the accident at the Tokyo Electric Power Company's Fukushima Daiichi Nuclear Power Plant, wide-range radiation monitoring via aircraft (hereinafter, airborne monitoring) was conducted in eastern Japan. An advantage of airborne monitoring is that it provides a "surface"-based understanding of air dose rates and deposition amount distributions of radioactive cesium by rapidly measuring gamma rays across a wide range, from urban areas to mountain forests, and the data are visually easy to understand. Through this airborne monitoring, in addition to the spatial dose rates and distribution of deposition amounts of radioactive cesium in each area of eastern Japan, we also gained an understanding of the air dose rate distribution of natural nuclides in eastern Japan, for which there have been no detailed measurement results until now. An overview of the wide range of airborne monitoring results in eastern Japan and the issues faced moving forward are explained herein.

\section{Introduction}

To evaluate the range of impact of radioactive substances that were emitted and diffused by the accident at the Fukushima Daiichi Nuclear Power Plant (hereinafter, the power plant), caused by the massive tsunami that hit the Pacific coast of Japan as a result of the Great East Japan Earthquake of March 11, 2011, Japan's Ministry of Education, Culture, Sports, Science and Technology (MEXT) and the United States Department of Energy conducted joint airborne monitoring and understood the air dose rates at a height of $1 \mathrm{~m}$ above ground and the status of radioactive cesium contamination at the ground surface within a range of $80 \mathrm{~km}$ from the power plant. Next, the group continued to conduct monitoring, including that of the surrounding area, and implemented airborne monitoring of the entire eastern Japan area (one metropolitan area, 21 prefectures) from Aomori Prefecture to Aichi Prefecture, including every prefecture surrounding Fukushima Prefecture, and understood the spatial dose rate distribution in the area and the contamination due to radioactive cesium on the ground surface ${ }^{1)}$.

DOI : 10.15669/fukushimainsights.Vol.1.202

(C) 2021 Atomic Energy Society of Japan. All rights reserved.

Originally published in Journal of the Atomic Energy Society of Japan (ISSN 1882-2606), Vol. 54, No. 3, p. 160-165 (2012)

in Japanese. (Japanese version accepted: January 7, 2012) 
In Japan, as indicated by the Environmental Radiation Monitoring Guidelines, airborne monitoring techniques were developed for use in the event of an accident at a nuclear power facility, but this experience of implementing large-scale measurements was the first of its kind. The U.S. Department of Energy provided guidance and advice regarding details such as measurement methods, and a measurement plan was devised while referencing various documents and groping about for additional information; sensitivity testing in regard to detection devices was conducted and airborne monitoring was conducted while developing analysis techniques. In this paper, we explain the knowledge that was gained through the airborne monitoring of the entire eastern Japan area implemented thus far, as well as the issues that remain.

\section{Details of Airborne Monitoring}

(1) Within a Range of $80 \mathrm{~km}$ from the Power Plant

As described below, primary to quaternary airborne monitoring was conducted in the area surrounding the power plant.

- First-stage Monitoring: The U.S. Department of Energy (hereinafter, "U.S. DOE") equipped a U.S. military aircraft (C-12, UH-1) with a large NaI detector (hereinafter, the DOE detector) and monitored an area within a radius of $60 \mathrm{~km}$ from the power plant (Figure 1). In addition, MEXT (The Nuclear Safety Technology Center, hereafter, NUSTEC) attached an NaI detector (hereinafter, the NUSTEC detector) to the outside of a helicopter and conducted similar measurements within a radius of $60-80 \mathrm{~km}$. (Implementation Period: April 6-29)

- Second-stage Monitoring: MEXT (NUSTEC) implemented measurements in an 80$100 \mathrm{~km}$ radius (up to $120 \mathrm{~km}$ for the southern part of Ibaraki Prefecture) using the NUSTEC detector. (Implementation Period: May 18-26)

- Third-stage Monitoring: The Japan Atomic Energy Agency (hereafter, JAEA) and NUSTEC equipped a helicopter (UH-60J) of the Japan Air Self-Defense Force with a DOE detector and conducted monitoring within a $40 \mathrm{~km}$ radius from the power plant. In addition, the Nuclear Safety Technology Center conducted monitoring using the NUSTEC detector within a 40 to $80 \mathrm{~km}$ radius. (Implementation Period: May 31 to July 2)

- Fourth-stage Monitoring: The distribution of radiation after being affected by the rainy season and typhoons was measured with the same system as that in the third-stage

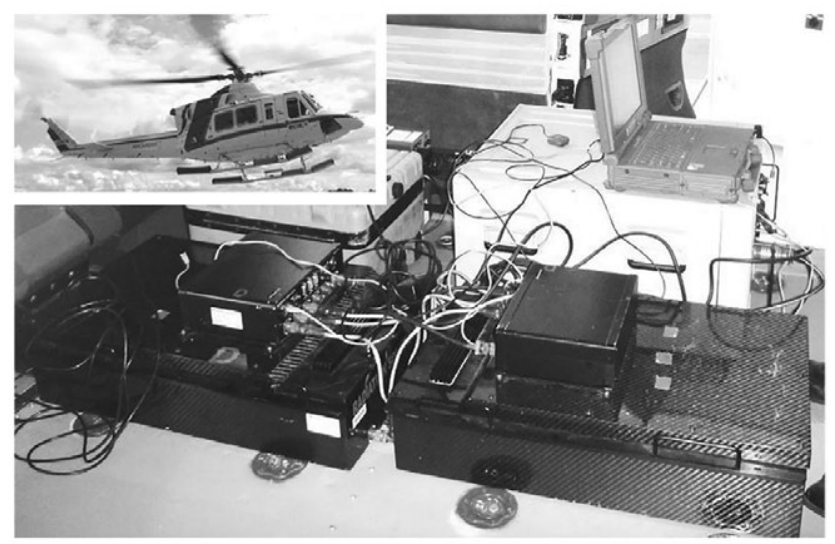

Figure 1 DOE detectors (two in the front), measuring instrument, batteries, and helicopter equipped with these instruments 
monitoring.(Implementation Period: October 24 to November 5)

\section{(2) Implementation in Entire Eastern Japan Area}

To understand the status of diffusion of radioactive substances beyond the $80 \mathrm{~km}$ radius of the power plant, airborne monitoring was conducted in one metropolitan area and 21 prefectures-from Aomori Prefecture to Fukui, Gifu, and Aichi Prefectures. To prevent any shielding of deposited radiation by snowfall, the goal was to complete the monitoring by mid-October and a decision was made to conduct monitoring with four helicopters including those equipped with the DOE detector and the NUSTEC detector and helicopters equipped with detectors obtained through the cooperation of two other companies (Oyo Corporation, Japan and FUGRO Co. Ltd. Australia). Details of the devices that were used are shown in Table 1.

Table 1 Detectors Used in Airborne Monitoring of the Entire Eastern Japan Area

\begin{tabular}{|c|c|c|c|c|c|}
\hline Detector Name & Loading Method & $\begin{array}{l}\text { Detector Size } \\
\text { (inches), Quantity }\end{array}$ & Energy Range & $\begin{array}{l}\text { Number of } \\
\text { Measurement } \\
\text { Channels }\end{array}$ & $\begin{array}{l}\text { Altitude } \\
\text { Measurements }\end{array}$ \\
\hline DOE Detector & Inside aircraft & $16 " \times 4 " \times 2 "$, qty. 6 & $0.02-3 \mathrm{MeV}$ & $1,024 \mathrm{ch}$ & GPS \\
\hline NUSTEC Detector & Outside aircraft & $16 " \times 4 " \times 4 "$, qty. 4 & $0.05-3 \mathrm{MeV}$ & $256 \mathrm{ch}$ & Laser \\
\hline OYO Detector & Outside aircraft & $16 " \times 4 " \times 4 "$, qty. 8 & $0.2-3 \mathrm{MeV}$ & $256 \mathrm{ch}$ & Radio waves \\
\hline FUGRO Detector & Inside aircraft & $16 " \times 4 " \times 4 "$, qty. 4 & $0.05-3 \mathrm{MeV}$ & $256 \mathrm{ch}$ & GPS \\
\hline
\end{tabular}

\section{Airborne Monitoring Method}

The monitoring was conducted on a prefecture unit beginning with the prefectures adjacent to Fukushima Prefecture. In addition, an airborne monitoring team for measuring the respective prefectures using four helicopters; an aboveground monitoring team for measuring the air dose rates at an altitude of $1 \mathrm{~m}$ and radioactive cesium concentration at the ground surface using in situ Ge detectors, and an analysis team for analyzing the dose rates at an altitude of $1 \mathrm{~m}$ from the airborne monitoring data, comparing and confirming with ground data, and mapping the data on maps were established. Through this, the air dose rates and deposition amounts of radioactive cesium were determined.

\section{Airborne Monitoring Devices and Measurements}

The large NaI detector shown in Table 1 was mounted either inside or outside of a helicopter; around two operators boarded each helicopter and the wave height distribution data for 256 or 1,024 channels was measured along with the total count rate [cps] every 1 s. Simultaneously, a GPS or another type of altimeter device was used to measure the positional information of the helicopter. To measure the altitude above ground, we used a method in which the altitude was either measured directly by a laser altimeter or a GPS altimeter was used to measure the flight altitude, and the difference from 90-m-mesh numeric map data (DEM: digital elevation model) was found and used as the altitude above ground.

Initially, in the measurements with the DOE detector for which the measuring instrument was installed inside the helicopter, one model of the helicopter was designed with the fuel tank installed under the cabin floor, but this required consideration of shielding by the fuel tank. Therefore, as a helicopter that used a detector that was installed inside the aircraft, a helicopter model without a fuel tank under the floor was selected for all helicopters.

To convert and evaluate the spatial dose rates at a height of $1 \mathrm{~m}$ from the total count rate 
obtained at the measurement altitude, a comparatively flat location at which the helicopters could be linearly flown for about $3 \mathrm{~km}$ was selected in advance as a test line. The helicopter was then flown in the skies above that level, with the altitude being changed every $150 \mathrm{~m}$ from an altitude above ground of $150 \mathrm{~m}$ (500 feet) to around 1,000 $\mathrm{m}(3,000$ feet) ; in this way, the effective air attenuation coefficient $\mu$ of radiation from aboveground was determined. In addition, the aboveground monitoring team conducted dose rate measurements (approximately five measurements were taken at each location, and the average value was calculated) at about 30 points using an NaI survey meter in an area with a width of $600 \mathrm{~m}$ and length of $3 \mathrm{~km}$ directly below the test line, and these measurements were compared with the airborne monitoring data to calculate the dose rate conversion coefficient [cps/ $(\mu \mathrm{Sv} / \mathrm{h})]$. Furthermore, cosmic rays and other such background compounds were identified by flying at an altitude near $300 \mathrm{~m}$ (above the water line) as a reference altitude above seawater (Figure 2).

As shown in Figure 3, in actual monitoring, flights were conducted in a series of parallele survey lines while maintaining an altitude of around 150 to $300 \mathrm{~m}$ above ground. The

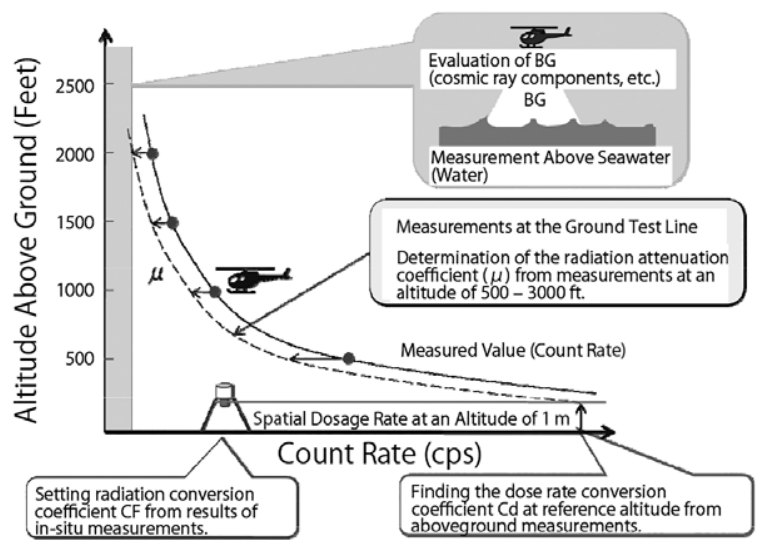

Figure 2 Measurement of radiation attenuation coefficient $\mu$ at the test line and that of the dose rate and conversion coefficient of radioactive cesium

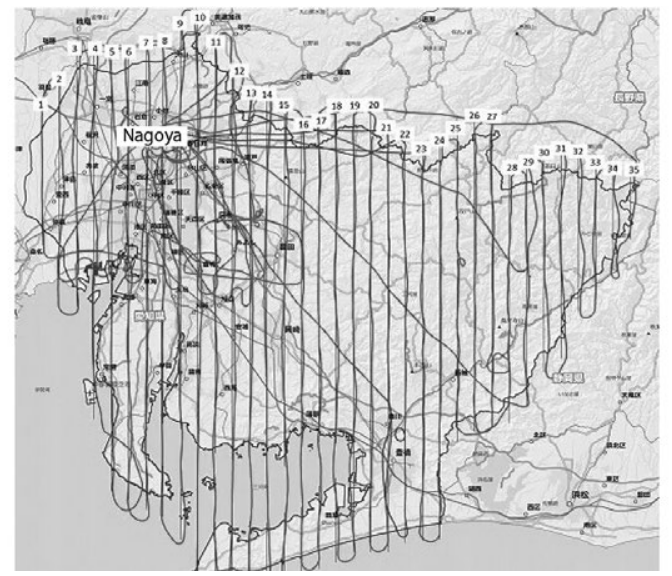

Figure 3 Flight Path Map in Aichi Prefecture Data obtained during movement from the airport and circling were not used and only data during linear flights were used in the analysis. The flight line spacing was $3 \mathrm{~km}$. 
measuring instruments loaded in the helicopters were not collimated, and gamma rays emitted from within a circle of the ground surface directly below with a radius that was about the same as the altitude above ground were measured. The flight line spacing within an $80 \mathrm{~km}$ range from the power plant was about $1.8-2 \mathrm{~km}$ (flights were partially conducted at a narrow survey line spacing with a width of $300 \mathrm{~m}$ ), and in other areas, as a general rule, measurements were conducted at around $3 \mathrm{~km}$. The flight path taken in Aichi Prefecture is shown in Figure 3.

\section{Analysis Method}

In the airborne monitoring conducted in this study, the energy spectrum data from gamma rays was collected, and to conduct a simple comparison with the aboveground air dose rates, the count rate in the entire energy area was used in the analysis. First, from the above-described air attenuation coefficient $\mu$ found at the test line, the dose rate conversion coefficient $C d[\mathrm{cps} /(\mu \mathrm{Sv} / \mathrm{h})]$ was found from a ratio of the count rate analysis value at a height of $1 \mathrm{~m}$ and the dose rate at a height of $1 \mathrm{~m}$ actually measured at ground level directly below the test line. This dose rate conversion coefficient $C d$ was then used to find the dose rate $D_{1 \mathrm{~m}}$ at a height above ground of $1 \mathrm{~m}$ from the airborne monitoring count rate and the altitude above ground $h$ using the following equation:

$$
D_{1 \mathrm{~m}}[\mu \mathrm{Sv} / \mathrm{h}]=e^{-\mu \mathrm{h}}\left(C_{\text {measured altitude }}[\mathrm{cps}]-B G_{\text {cosmic rays, etc. }}[\mathrm{cps}]\right) / C d
$$

Next, the concentration $V_{\mathrm{Cs}-134 / 137}$ of radioactive cesium (Cs-134, Cs-137) deposited on the ground surface was calculated by determining the conversion coefficient $C F\left[\left(\mathrm{kBq} / \mathrm{m}^{2}\right) /\right.$ $(\mu \mathrm{Sv} / \mathrm{h})]$ for the deposition of radioactive cesium on the ground surface with respect to the air dose rate from measurements using an in-situ Ge detector directly under the test line, and then subtracting the background dose rate contributed by natural nuclides (the background dose rate at the contaminated areas is unclear, and therefore, an average value of the spatial air dose rates for the past four years (2005 to 2008) obtained by radiation level surveys for the entire eastern Japan area was used) from the spatial dose rate at a height of $1 \mathrm{~m}$ (the data are presented in reference 2).

$$
V_{\mathrm{Cs}-134 / 137}=C F\left(D_{1 \mathrm{~m}}[\mu \mathrm{Sv} / \mathrm{h}]-B G_{\text {natural nuclides }}[\mu \mathrm{Sv} / \mathrm{h}]\right)
$$

\section{Method for Subtracting the Contribution Portion of Natural Nuclides}

As described above, in airborne monitoring, the dose rate at an altitude of $1 \mathrm{~m}$ was found from the total count rate, and the radioactive cesium deposited at the ground surface was calculated. As a result, as with the mountainous region of Niigata Prefecture, regardless of not detecting a significant energy spectrum for radioactive cesium, in areas for which the contribution of natural nuclides such as potassium, uranium, and thorium was higher than the average background dose rate ${ }^{3)}$, sites that were displayed on the map as if having a significant presence of radioactive cesium were observed on the map. Therefore, in airborne monitoring in Niigata Prefecture, the surrounding energy spectra were confirmed to be centered on sites where the spatial dose rates were high, measurement results for areas where a significant energy spectrum of radioactive cesium was not detected were not used, and the deposition amounts of radioactive cesium were corrected and mapped. However, while advancing with 
monitoring, there was a wide range of areas where a significant energy spectrum of radioactive cesium was not detected, such as Nagano Prefecture, Shizuoka Prefecture, Gifu Prefecture, and Toyama Prefecture, and therefore, it was difficult to identify areas where significant energy spectra of radioactive cesium were not detected using the same technique that was used when the airborne monitoring results were prepared for Niigata Prefecture. Therefore, for each measurement helicopter and each measuring instrument, techniques were examined for identifying areas where significant energy spectra were not detected for radioactive cesium.

Regarding areas where significant energy spectra of radioactive cesium were detected and those where they were not detected, as indicated by the following equation, the count rates were compared for energy areas that contained radioactive cesium energy spectra (areas with a gamma ray energy of $450 \mathrm{keV}$ or greater) and gamma ray energy areas attributed to natural nuclides containing almost no radioactive cesium (areas with energy of $900 \mathrm{keV}$ or greater).

$$
\text { Spectrum Index }=\frac{\text { Count Rate of } 450 \mathrm{keV} \text { or greater }}{\text { Count Rate of } 900 \mathrm{keV} \text { or greater }}
$$

The count rate ratio (hereinafter, spectrum index) of these areas differs depending on the presence or lack of radioactive cesium, and this difference was used to examine whether an area for which a significant energy spectrum of radioactive cesium was not detected could be identified.

Here, $450 \mathrm{keV}$ was selected as an energy level with minimal fluctuation because peaks of gamma rays emitted from Cs-134 and Cs-137 (Ba-137m) are not present, gamma ray peaks derived from natural nuclides are not visible; $900 \mathrm{keV}$ was selected because it is an energy level that is not affected by Cs-134 gamma ray peaks (796 keV).

As a method for evaluating low-contamination areas, the U.S. DOE developed the Man Made Gross Counts (MMGC) method ${ }^{4}$, and as the energy range for evaluating natural nuclides, this method uses a range at or above $1,400 \mathrm{keV}$. In this area, the count rate is low; therefore, the detection lower limit value is high, and because considerable data for non-contaminated areas are necessary, and due to issues with evaluating the deposition amounts, a method that uses the spectrum index was selected for this analysis rather than the MMGC method.

As a result, from a histogram of the spectrum index in areas where a significant radioactive cesium energy spectrum was not detected, it was confirmed that, while differences exist in the spectrum index average values and in the standard deviation thereof depending on the helicopter and type of measuring instrument that was used in the measurements, the data were distributed in a normal distribution centered on the average value. Figure $\mathbf{4}$ shows a case involving a prefecture for which the impact of radioactive cesium was large and a case involving a prefecture for which the impact was small. This image clearly shows that in prefectures where the cesium impact is large, in many areas, as the count rate increases, the spectrum index also increases; in contrast, in prefectures where the cesium impact is small, an almost normal distribution is observed (Figure 4, left).

Therefore, to specify areas where a significant energy spectrum of radioactive cesium was not detected, a reference value (average value $+3 \sigma$ ) for the spectrum index was established for each type of helicopter and measuring instrument used in the measurements, and it was determined that radioactive cesium gamma rays were significantly detected only for cases in which this index exceeded the reference value.

For comparison, data for Niigata Prefecture prior to correction and for which this 
technique was not used, as well as analysis data for which this technique was used, are shown in Figure 5. From the results, in areas such as the northern part of Niigata Prefecture, through the application of this technique, it was determined that much of the radiation was due to the contribution of gamma rays from natural nuclides, and it was determined that, in most areas, significant radioactive cesium was not deposited $\left(\leqq 10 \mathrm{kBq} / \mathrm{m}^{2}\right)$.

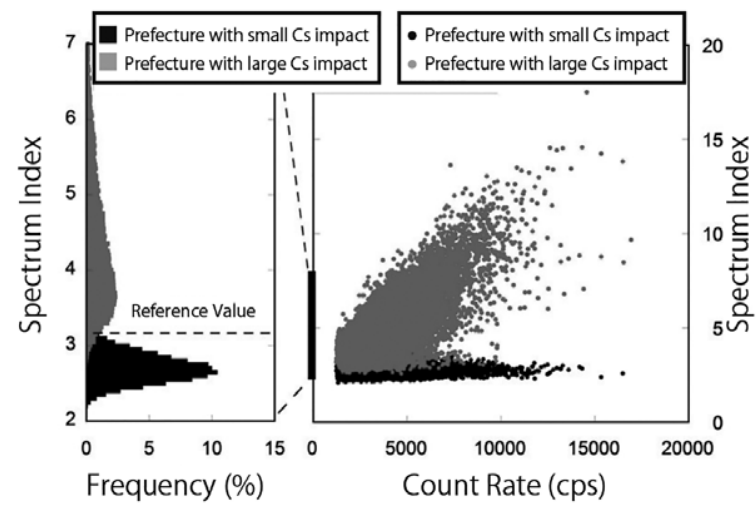

Figure 4 Difference in Spectrum Indexes of Measurement Data Based on Magnitude of Radioactive Cesium Impact

(Left: Frequency Distribution, Right: Correlation with Count Rate)
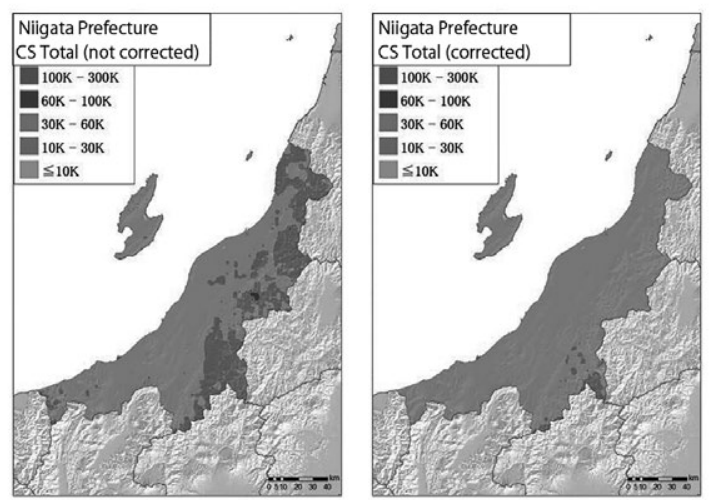

Figure 5 Total Radioactive Cesium Deposit Amount in Niigata Prefecture

Left is a map calculated from dose rates before correction, and the right shows results analyzed using the spectrum index.

\section{Results}

\section{Air Dose Rates and Deposition Amount of Radioactive Cesium}

The helicopters flew at a speed of about 130-148 km/h (70-80 knots), and sampled data every second; therefore, the measurement point interval was several tens of meters. Since the flight spacing was around $3 \mathrm{~km}$, it significantly exceeded the range of measurement obtained 
by the measuring instruments. Thus, it became necessary to find the air dose rates and "surface" distribution of the contamination due to radioactive cesium by interpolating the measurement results. To this end, the measured values for 180 points near the area that were to be analyzed were extracted and the inverse distance weighted method was used for evaluations, assuming that the weighting decreased as the distance from the point increased. A map of the air dose rate distribution for the entire eastern Japan area obtained through this technique is shown in Figure 6 (left). The results clearly show that areas with high spatial dose rates expand in the northwest direction from the power plant and expand from near the city of Fukushima to Gunma Prefecture in the southwest direction. In addition, from the southern parts of Iwate Prefecture and Ibaraki Prefecture to the northern part of Chiba Prefecture, a region with relatively high air dose rates of $0.1-0.2 \mu \mathrm{Sv} / \mathrm{h}$, thought to be due to the deposition of radioactive cesium, was observed. Furthermore, areas with relatively high spatial dose rates were also found scattered throughout areas such as Gifu Prefecture and Toyama Prefecture; however, many of these areas coincide with geological data thought to be granite, and are therefore thought to be due to the impact of natural nuclides. Therefore, as a result of examining the spectrum indexes, in most of these areas, the index is at or below the reference value, and thus, majority of the air dose rates are attributed to natural nuclides. Furthermore, as shown in Figure 6 (right panel), the deposition amount of radioactive cesium is $10 \mathrm{kBq} / \mathrm{m}^{2}$ or less.

\section{Map Usage Method}

A map of the air dose rates and radioactive cesium deposition amounts is always posted on the MEXT homepage ${ }^{1)}$. This is visually easy to understand, and therefore, can be used for
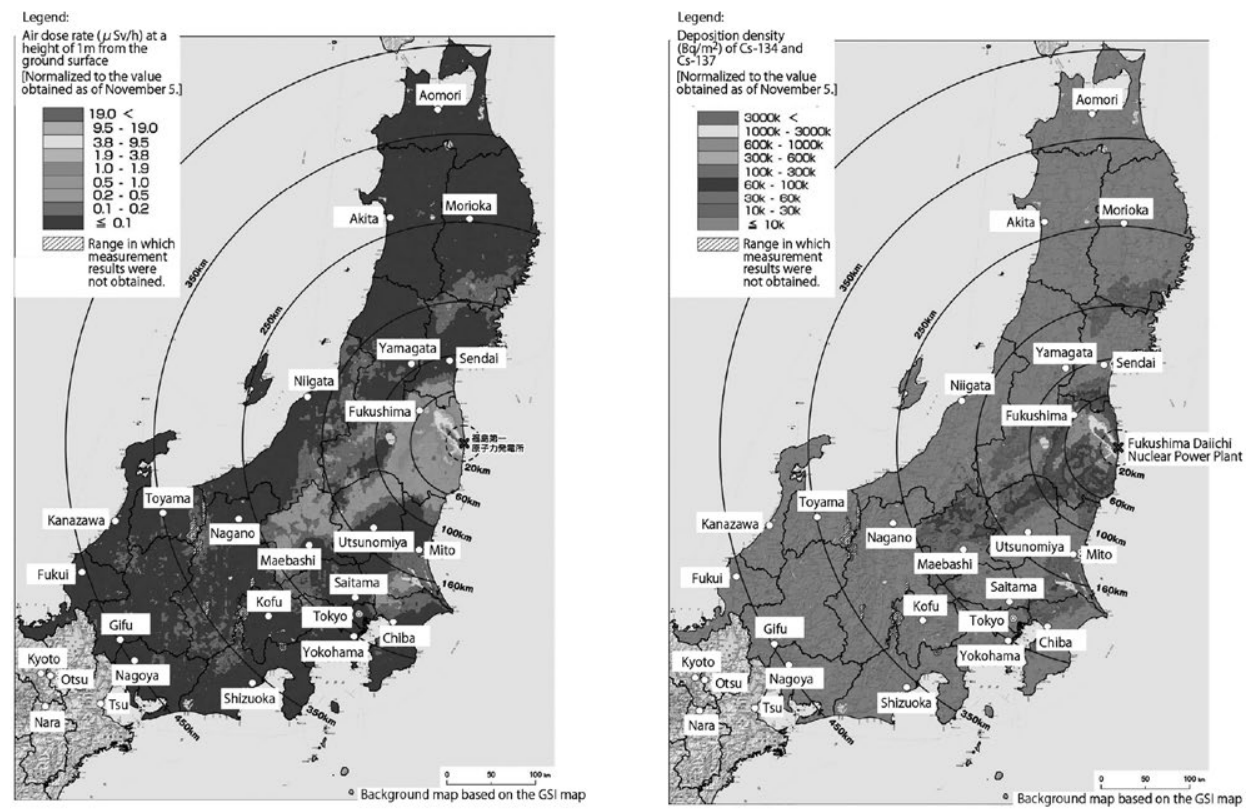

Figure 6 Analysis Results of Wide-Area Monitoring in Eastern Japan Area Reflecting Quaternary Monitoring in $80 \mathrm{~km}$ Range

Air dose rates at height of $1 \mathrm{~m}$ (left) and total amount of deposition of radioactive cesium (Cs-134, Cs-137) at ground surface (right). 


\section{INSIGHTS CONCERNING THE FUKUSHIMA DAIICHI NUCLEAR ACCIDENT Vol. 1}

various purposes.

For example, it can be used for producing an anticipated dose rate map after several years based on the physical half-life of radioactive cesium (Figure 7). In fact, in addition to physical decay, attenuation and fluctuation due to natural causes and decontamination are anticipated, and therefore, monitoring must be continued in the future and changes must be monitored by mapping the obtained data.

Moreover, attention can be focused topographically on the deposited amounts of radioactive cesium, and three-dimensional distributions can be created. As shown in Figure 8,
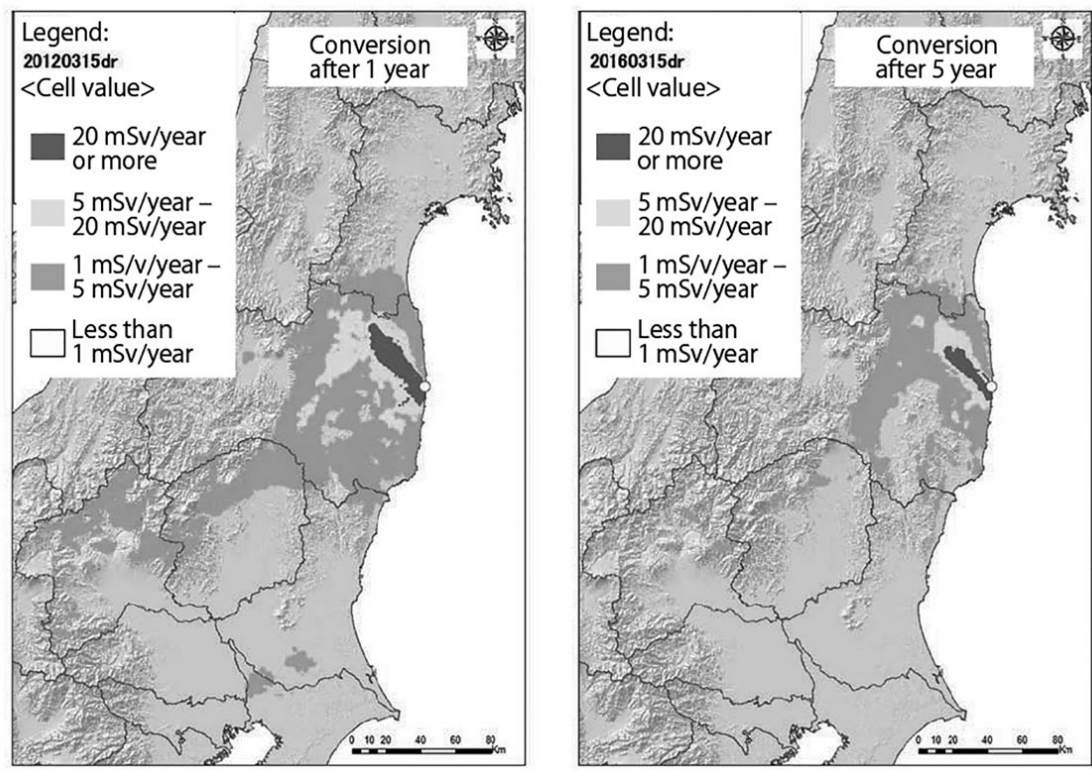

Figure 7 Dose Rate Maps (after 1 year, after 5 years) Corresponding to 1-20 mSv/year or Greater, Converted from Airborne Monitoring Results
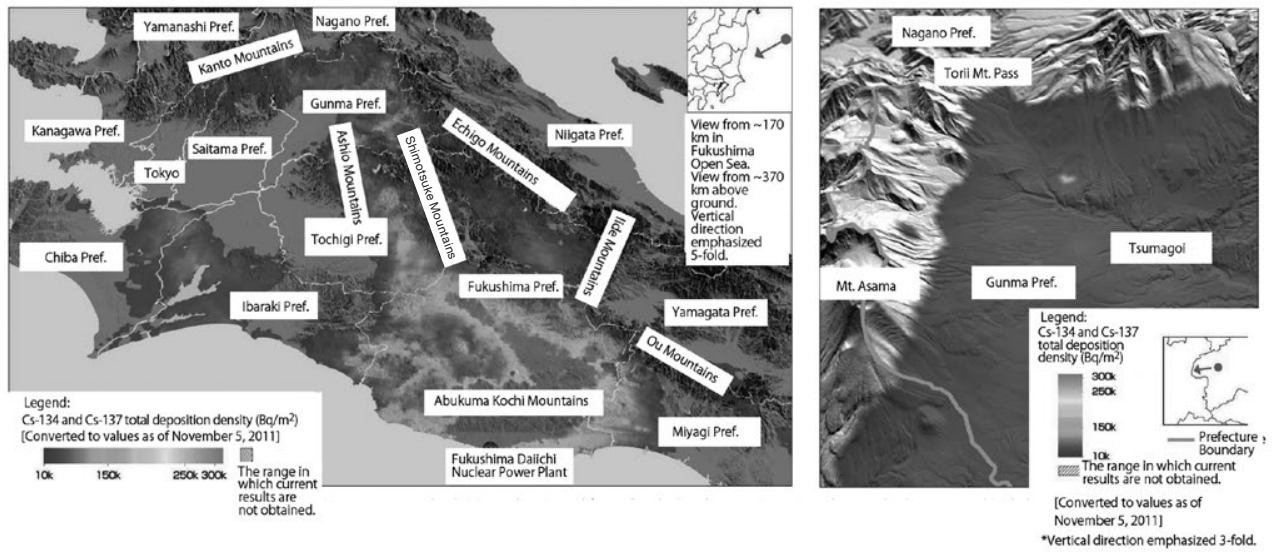

Figure 8 Bird's-eye View of Radioactive Cesium Deposit Amounts (Left: View from Open Sea at Fukushima Prefecture, Right: Near Borders of Gunma and Nagano prefectures)

※The topographical relation of measurement values for which the radioactive cesium deposition amount is $10 \mathrm{kBq} / \mathrm{m}^{2}$ or less is not depicted in order to the relation be easily confirmed. 
radioactive cesium emitted into the atmosphere is diffused and deposited along the Ou Mountain Range, the Iide Mountains, the Echigo Mountain range, the Shimotsuke Mountains, and the Kanto Mountains. In addition, the main deposition locations have an elevation that is lower than $1,000 \mathrm{~m}$, and therefore, it is inferred that the deposition did not exceed high elevations such as that of the Torii Mountain Pass with an elevation of 1,400 m for the most part.

\section{Future Issues}

This is the first study in which airborne monitoring was implemented over a wide range of eastern Japan; as a result, the distribution of surface radiation was made clear and the status of air dose rates and distribution of deposition amounts of radioactive cesium in each region thus far was confirmed. In addition, through these measurements, we confirmed the effects of natural nuclides in eastern Japan, for which detailed measurement results did not exist until now.

However, during the implementation of this monitoring, several issues, including the method for subtracting natural nuclides, became clear.

\section{Altitude Above Ground and Topographical Effects}

The airborne monitoring results confirmed a close match between data of approximately 2,200 points obtained by aboveground measurements within a range of $80 \mathrm{~km}$ from the power plant ${ }^{5)}$ and those from approximately 100 points of aboveground measurement results in the entire eastern Japan area. While there was some deviation with ground measurement results in mountainous areas and valleys, the ratio of ground measurements and airborne monitoring measurement results was generally within a range of $0.5-1.5$, indicating good agreement.

However, a large portion of Japan comprises mountainous areas, and in steep terrain, radiation is measured not only from directly below the measurement point but also from an inclined direction. In valleys, there is significant contribution from the inclined direction as well from a distance and surface area perspective, and in such locations, it is possible that the air dose rates were analyzed on the high side.

Therefore, moving forward, in order to increase the precision of airborne monitoring, the impact of topographical effects must also be evaluated.

\section{Impact of Cosmic Rays}

The dose rates with airborne monitoring were evaluated upon subtracting the contribution from cosmic rays. Here, the contribution portions of the cosmic rays were determined by an above-water line not affected by gamma rays from aboveground, and the value thereof (constant value) was subtracted. However, the amount of contribution from cosmic rays changes depending on the flight altitude, and in mountainous areas with high elevations, such as Nagano Prefecture and Gifu Prefecture, the ground air dose rates might be evaluated somewhat on the high side. Therefore, to improve precision, an evaluation method must be developed in the future. 


\section{Conclusions}

Airborne monitoring was conducted by JAEA as work commissioned by the MEXT FY 2011 Radiation Measurement Survey Committee for a "Survey of the Status of Radioactive Substance Diffusion Using Aircraft for Wide Range Environmental Monitoring," and the results were compiled. Over 80 people from various organizations and private companies including JAEA, NUSTEC, the Japan Map Center, and the Oyo Corporation participated in this effort by riding in helicopters to conduct measurements, conduct aboveground air dose rate measurements and in-situ measurements, and analyze and map the acquired data. In addition, cooperation for flights around the nuclear power plant was obtained from the Hyakuri Air Rescue Squadron of the Japan Air Self-Defense Force, and that for flights around Miyagi, Yamagata, Tochigi, Gunma, and Ibaraki prefectures was obtained from the disaster prevention flying corps from each prefecture and from Aero Asahi and Nakanihon Air Service. We express our sincere gratitude to all those who participated in this monitoring. We are also deeply grateful to MEXT Nuclear Emergency Countermeasures Support Headquarters Monitoring Team Leader Shuichiro Itakura and Daichi Saito, who planned and encouraged this monitoring project.

\section{References}

1) Airborne Monitoring Results by MEXT (Including cooperation by the U.S. Department of Energy) (http://radioactivity.mext.go.jp/ja/monitoring_around_FukushimaNPP_MEXT_DOE_airborne_monitoring/). [in Japanese] present web site is http://radioactivity.nsr.go.jp/en/list/307/list-1.html released by Nuclear Regulation Authority, Japan

2) Environmental Radiation Database (http: //search.kankyo-hoshano.go.jp/servlet/search.top). [in Japanese]

3) Hata S. Ground Surface Gamma Ray Dose Rate Distributions in Japan Chigaku-Zasshi (Journal of Geography).2006;115(1), 87-95. [in Japanese]

4) Hendricks T.J. et al. An Aerial Radiological Survey of the Nevada Test Site 1999;DOE/NV/11718 324.

5) Preparation by MEXT of Distribution Maps of Radiation Amounts, Etc. (Dose Measurement Maps) (http://radioactivity.mext.go.jp/ja/distribution_map_around_FukushimaNPP/0002/5600_080218.pdf). [in Japanese] 